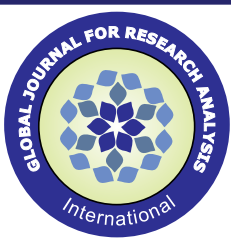

\section{Dr. Priti Singh*}

\section{Dr.Krishna Sinha}

\title{
STUDY OF OBSTETRIC OUTCOME IN ASSOCIATION WITH HEIGHT OF WOMEN
}

\section{ABSTRACT} randomly selected. After consident Results of the two groups compared in relation to obstetric outcome and fetal weight.
Senior Resident, Dept. of Obs. and Gynae., JLN medical College, Bhagalpur . ${ }^{*}$ Corresponding Author

Associate Professor, Dept. of Obs. and Gynae. , JLN medical College, Bhagalpur.

KEYWORDS : Obstetric outcome, short stature woman

\section{INTRODUCTION}

During the past few years attempts are made to identify risk factors that could place women at higher level of care and so as to improve their obstetric outcome. A physical parameter that was highlighted years ago but has received less attention is maternal height. Short stature has drawn attention of obstetricians throughout world because of its potential in causing significant adverse birth outcomes.

The stature of an individualis decided by factors like nutritional status, genetic, developmental, racial, evolutionary, endocrinal,skeletal,socioeconomic status. A short stature women is likely to have contracted pelvis, cephalopelvic disproportion, malpresentations, prelabour rupture of membrane,obstructed labour, rupture uterus with an increased incidence of instrumental and operative deliveries. There is also an increased incidence of perinatal morbidity and mortality. In developing country like India majority of rural women are ill nourished and belong to poor socioeconomic status, hence are short stature. According to WHO, $\mathrm{Ht}<140 \mathrm{~cm}$ has been taken as a high risk for pregnancy. In western countries, $\mathrm{Ht}<150 \mathrm{~cm}$ has been taken as short stature, But in India height $<145 \mathrm{~cm}$ has been taken as short stature.

\section{MATERIAL AND METHOD}

The patients are recruited from the OPD and LABOUR ROOM of the O \& G Dept. of JLNMCH , Bhagalpur, Bihar for a study period of one year. It was a cross-sectional, case-control study. 250 full term primigravida without any obstetric and medical complications were randomly selected for the study. All the cases were with the gestational age $\geq 37$ weeks who had spontaneous onset of labor

EXCLUSION CRITERIA : Those pregnancies with medical or obstetric complications or those with fetal anomalies or fetal death or elective Cesarean Section excluded from the study.

Patient asked to sign the consent form once they have understood the content completely.

After considering these inclusion and exclusion criteria 250 cases elected, out of which 144 cases underwent emergency LSCS formed the study group, and rest 106 who gave birth vaginally formed the control group.

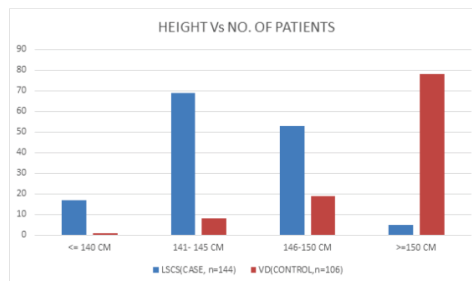

\section{OBSERVATION}

Distribution Of Patients Ass Per Height In Both Groups

\begin{tabular}{|l|l|l|}
\hline HEIGHT(CM) & CASE(n=144) & CONTROL(n=106) \\
\hline$<=140$ & $17(11.80 \%)$ & $1(0.94 \%)$ \\
\hline 141 TO 145 & $69(47.92 \%)$ & $8(7.55 \%)$ \\
\hline 146 TO 150 & $53(36.81 \%)$ & $19(17.93 \%)$ \\
\hline$>150$ & $5(3.47 \%)$ & $78(73.58 \%)$ \\
\hline
\end{tabular}

In present study, out of 144 patients from the study group, 17 (11.80\%) had the height $<140 \mathrm{~cm}, 69(47.92 \%)$ between 141 and $145 \mathrm{~cm}, 53(36.81 \%)$ had height $146-150 \mathrm{~cm}$ and $5(3.47 \%)$ had the height $>150 \mathrm{~cm}$. In the control group, out of 106 patients, $1(0.94 \%)$ patient belonged to $<140 \mathrm{~cm}, 8(7.55 \%)$ between 141 and $145 \mathrm{~cm}, 19$ (17.93\%) patients in between 146 and $150 \mathrm{~cm}$ and rest $78(73.58 \%)$ had height $>150 \mathrm{~cm}$. The difference between study group and control group was found to be statistically significant $(P<0.05)$. In the study group, mean height was $144.78 \mathrm{~cm}$, while in the controls it was $156.46 \mathrm{~cm}$.

\begin{tabular}{|c|c|c|c|c|}
\hline \multirow{2}{*}{$\begin{array}{c}\text { HEIGHT } \\
(\mathrm{CM})\end{array}$} & \multicolumn{3}{|c|}{ MODE OF DELIVERY } & \\
\cline { 2 - 5 } & $\begin{array}{c}\text { Spontaneous } \\
\text { vaginal } \\
\text { delivery }\end{array}$ & $\begin{array}{c}\text { Instrumental } \\
\text { delivery }\end{array}$ & LSCS & Total \\
\hline$<=145$ & $7(7.33 \%)$ & $2(2.15 \%)$ & $86(90.52 \%)$ & $95(100 \%)$ \\
\hline 146 to 150 & $16(22.22 \%)$ & $3(4.16 \%)$ & $53(73.62 \%)$ & $72(100 \%)$ \\
\hline$>150$ & $69(83.13 \%)$ & $9(10.84 \%)$ & $5(6.03 \%)$ & $83(100 \%)$ \\
\hline
\end{tabular}

95 patients had height $<145 \mathrm{~cm}$. Out of them 7 (7.33\%) delivered spontaneously vaginally, $2(2.15 \%)$ cases had undergone instrumental delivery, while 86 (90.52\%) cases undergone caesarean delivery. In the maternal height of 146$150 \mathrm{~cm}$ among 72 cases, 16 (22.22\%) cases of spontaneous vaginal delivery, $3(4.16 \%)$ cases instrumental delivery while $53(73.62 \%)$ of cases caesarean delivery done. In the maternal height of $\geq 150 \mathrm{~cm}$ out of 83 cases, $69(83.13 \%)$ cases delivered spontaneous vaginally, $9(10.84 \%)$ instrumental delivery while $5(6.03 \%)$ cases LSCS done. Hence it can be seen that with the decrease in maternal height, chances of caesarean delivery increases. Using Chi-square test, $(P<0.05)$ the difference was found statistically significant.

\section{CASE $(n=144)$}

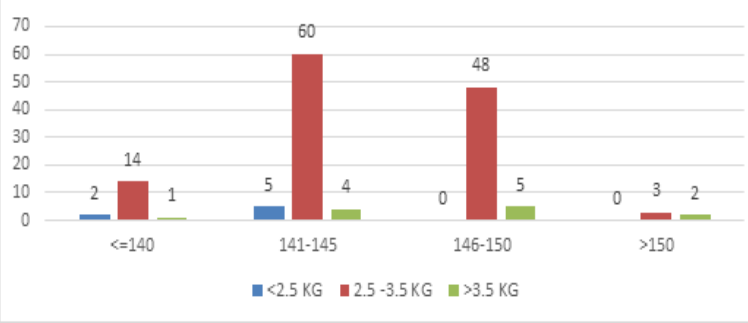




\begin{tabular}{|l|l|l|}
\hline Fetal weight & Case $(\mathrm{n}=144)$ & Control $(\mathrm{n}=106)$ \\
\hline$<2.5 \mathrm{~kg}$ & 7 & 11 \\
\hline 2.5 to $3.5 \mathrm{~kg}$ & 125 & 92 \\
\hline$>3.5 \mathrm{~kg}$ & 12 & 3 \\
\hline
\end{tabular}

In the present study, mean estimated weight in the study group was $2928 \mathrm{~g}$ while in the control group it was $2756 \mathrm{~g}$.

$\operatorname{CONTROL}(\mathrm{n}=106)$

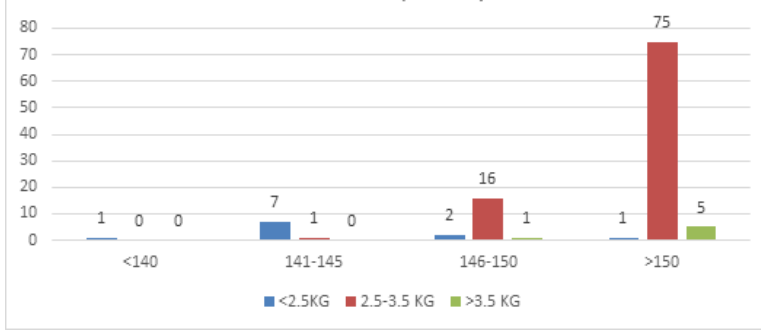

By applying Chi-square test, the difference was found to be significant $(\mathrm{P}<0.05)$. Women with lesser height and more baby weight are more likely to go for caesarean delivery.

Higher the maternal height range $(>150 \mathrm{~cm})$ and lower estimated fetal weight range $(<2.5 \mathrm{~kg})$ almost all babies were delivered vaginally. In the same way, lower maternal height range $(<145 \mathrm{~cm})$ and higher estimated fetal weight range (2.5$3.5 \mathrm{~kg})$, almost all babies are delivered by caesarean section.

\begin{tabular}{|l|l|l|l|}
\hline Height $(\mathrm{cm})$ & LSCS & VD & Total \\
\hline$<=145$ & $86(90.52 \%)$ & $9(9.48 \%)$ & $95(100 \%)$ \\
\hline$>145$ & $58(37.41 \%)$ & $97(62.59 \%)$ & $155(100 \%)$ \\
\hline
\end{tabular}

So it can be concluded that the incidence of caesarean delivery in women with height $145 \mathrm{~cm}$ or less was significantly higher $(90.52 \%)$ than those with height more than $145 \mathrm{~cm}$ (37.41\%).

Thus, women who are $\leq 145 \mathrm{~cm}$ have more risk of caesarean delivery when compared to females of more than $145 \mathrm{~cm}$ height.

\section{DISCUSSION}

The present study suggests that women of short stature belong to a higher risk group regarding obstetric outcome. The rate of LSCS in short statured women was significantly higher than that of taller women $(90.52 \%$ vs $9.48 \%)$. Mahmood et al ${ }^{4}$ also found a significantly higher rate of LSCS in women of short stature. Kappel et $\mathrm{al}^{9}$ and by LY Hin et $\mathrm{al}^{10}$ observed that the prevalence rate for emergency LSCS was 3-fold higher in short mothers.The vaginal delivery rate in short mothers was lower than that in taller women (9.48\% vs $62.59 \%)$.Similar observations were made by Desai et $\mathrm{al}^{8}$.

Baird $^{13}$ postulates that every female has a potential height, which decided by factors such as race, genetics, and geographic distribution. However, there occur certain insults that are exclusively dominant, if it is so during her age of development. As a result of which she becomes short stature or long In the present study, mean estimated weight in the study group was $2928 \mathrm{~g}$ while in the control group it was $2756 \mathrm{~g}$. Females with lesser height and larger baby were more likely to go for the caesarean section. Karltreinder ${ }^{14}$ also found that taller females tend to produce heavier children in contrast to the shorter females who tend to produce lighter ones Babies weighing $>3.5 \mathrm{~kg}$ were more in tall mothers compared with short mothers. But the difference in the incidence of $<2.5 \mathrm{~kg}$ in both groups was almost similar. Similar observation was made by T Kamaldoss et al ( 1992 $)^{15}$ where the incidence of LBW babies among mothers with height $<145$ and $>145$ were $29.7 \%$ and $24.2 \%$ respectively.

In short mothers, rate of LSCS increased significantly with increase in birth weight of the baby. The possibility of vaginal delivery decreases as the baby weight increases in mothers with short stature. In the present study, 9 cases $(9.48 \%)$ of the short mothers delivered vaginally. Among them 8 had babies of $<2.5 \mathrm{~kg}$ and 1 had $2.8 \mathrm{~kg}$ baby were delivered through. This explains the fact that vaginal delivery is possible in short women when they have small babies.

\section{CONCLUSION}

Poor obstetric outcomes are commoner among short statured women. Mode of delivery is influenced by maternal height and fetal weight. The short statured females are more likely to undergo LSCS for CPD. Even though significant number of larger babies is born to taller mothers but this does not signify that short mothers are at risk of having LBW babies. In mothers with short stature, rate of LSCS increases and vaginal delivery decreases as the birth weight of the baby increases. The need for assessment of height, partographic monitoring, prompt diagnosis of cephalopelvic disproportion and early decision of caesarean section is needed to prevent the adverse maternal and perinatal morbidity and mortality in short statured mothers.

\section{REFERENCES}

1. Textbook of Obstetrics, D.C. Dutta, 7th Edition ,P-631-632

2. William's Obstetrics, 22nd Edition.

3. Sylvia kirchengast,Beda Hartman; Short stature is asso with an increased risk of caesarian deliveries in low risk population;ACTA MEDICA LITUANICA. 2007,vol.14 no.l,p.l-6

4. Mohamed Ahmed A/Gadir elimam et al;Age,anthropometric measurements and mode of delivery in nulliparous women at Omdurman materity hospital;Khartoum medical journal(2010) vol.03,no.03,pp.489-492.

5. Literature review; Indicators for high risk pregnancy.

6. A.A.G. Jimoh(2001);Obstetric height at risk;A need for rethink and experience at the university of Ilorin teaching hospital;The tropical journal of health sciences, vol.8(2001),p.32-36.

7. Bruno Dujardin et al;The value of maternal height as a risk factor of dystocia; a meta-analysis;Tropical medicine and international health;vol.1,no-4,pp.510-521,August 1996.

8. Desai P, Hazra M, Trivedi LB. Pregnancy outcome in short statured women. J Indian Med Assoc 1989;87(2):32-4.

9. Kappel B, Eriksen G, Hansen KB, et al. Short stature in scandinavian women. An obstetrical risk factor. Acta Obstet Gynaecol Scand 1987;66(2):153-8.

10. Hin LY, Khairuddin Y, Ng KB. The predictive value of extremes of birth weight, mother's height and ethnic origin on the likelihood of emergency caesarean section. Asia Oceania J Obstet Gynaecol 1994;20(4):389-94.

11. Parsons MT, Winegar A, Siefert L, et al. Pregnancy outcome in short women. J Reprod Med 1989;34(5):357-61.

12. Pradhan N, Dali S. Pregnancy outcome in relation to the height of Nepalese women. J Inst Med 1992; 14:179-91.

13. Baird D. Environmental and Obstetrical factors in prematurity with special reference to experience in Aberdeen. WHO Tech Rep Ser. 1962;26:291-5.

14. Frank K. "Effect-Height-Weight-Pregnancy- Newborn", Monogram, 1963.

15. Theodore K, Able R, Sampath Kumar V. Epidemiological correlates of low birth weight rural Tamil Nadu. Indian J Pediatr 1992;59:299-30 